\title{
Rudimentary horn pregnancies: dilemmas in diagnosis
}

\section{Yashodhara Gaur*, Prakriti Goswami, Karuna Meravi}

Department of Obstetrics and Gynecology, G.R. Medical College, Gwalior, Madhya Pradesh, India

Received: 01 June 2017

Accepted: 27 June 2017

\section{*Correspondence:}

Dr. Prakriti Goswami,

E-mail: goswami.prakriti@gmail.com

Copyright: (c) the author(s), publisher and licensee Medip Academy. This is an open-access article distributed under the terms of the Creative Commons Attribution Non-Commercial License, which permits unrestricted non-commercial use, distribution, and reproduction in any medium, provided the original work is properly cited.

\begin{abstract}
Rudimentary horn pregnancy is a rare obstetric entity and the diagnosis and management may pose some problems especially in a low-resource center. We report a case of G1P0 with pregnancy of 28 weeks gestation with diagnosed intrauterine fetal death, which was suspected as extra uterine pregnancy bases on failed attempts of termination of pregnancy and on laparotomy, a dead fetus of 16 weeks was found in left unruptured noncommunicating horn of unicornuate uterus. Diagnosis of rudimentary horn pregnancy is difficult and can be missed in ultrasound. It requires a high index of suspicion.
\end{abstract}

Keywords: Intrauterine fetal death, Rudimentary horn, Unicornuate uterus

\section{INTRODUCTION}

Mullerian anomalies were first classified in 1979 by Buttram and Gibbons and further revised by the American Society of Reproductive Medicine in 1988. Unicornuate uterus is a type 2 classification with unilateral hypoplasia or agenesis that can be further subclassified into communicating, noncommunicating, no cavity, and no horn. ${ }^{1}$ The incidence of uterine congenital anomalies because of Mullerian defects in the normal fertile population is $3.2 \%$. A unicornuate uterus accounts for $2.4 \%-13 \%$ of all Mullerian anomalies. ${ }^{2} 72-85 \%$ of the rudimentary horns are noncommunicating with the cavity. ${ }^{3}$ Unicornuate uterus with rudimentary horn may be associated with gynaecological and obstetric complications like infertility, endometriosis, haematometra, urinary tract anomalies, abortions, and preterm deliveries. Rupture during pregnancy is the most dreaded complication which can be life threatening to the mother. We report a case of unruptured rudimentary horn pregnancy which was ultrasonographically diagnosed as intrauterine fetal death, laparotomy was taken after failed attempts at termination of pregnancy, and managed by resection of rudimentary horn.

\section{CASE REPORT}

A 21 yrs old G1P0 was admitted in Kamla Raja hospital, Gwalior with Amenorrhoea 7 months with diagnosed intrauterine fetal death of 16 wk 4 days, with moderate anaemia, with spotting PV on and off for one month. There was no history of any fall or trauma to the abdomen. There was no associated hardening of uterus. She was unable to perceive fetal movements. Her marital life was 4 yrs. She conceived spontaneously. Her menstrual cycles were regular 30 days cycle in which she bleeds for 2-3 days and changed 2 pads per day. She gave history of three packed cell transfusions at a peripheral centre, one month prior to present admission. She was also diagnosed to have intrauterine fetal death and was advised termination, however patient refused and continued her pregnancy.

On admission, patient had mild pallor, no icterus, pulse rate was $88 / \mathrm{min}$, blood pressure $-110 / 70 \mathrm{~mm} \mathrm{Hg}$ and 
respiratory rate was $12 / \mathrm{min}$. On abdominal examination, uterine size was 16 - weeks. Surface was smooth, nontender and non-mobile. On per speculum examination, cervical os was posteriorly placed, no active vaginal bleeding. There was no cervical or vaginal pathology seen. On per vaginum examination, cervix was firm, $2.5 \mathrm{~cm}$ long and the os was closed. Routine blood investigations, LFT, RFT and coagulation profile of the patient were sent.

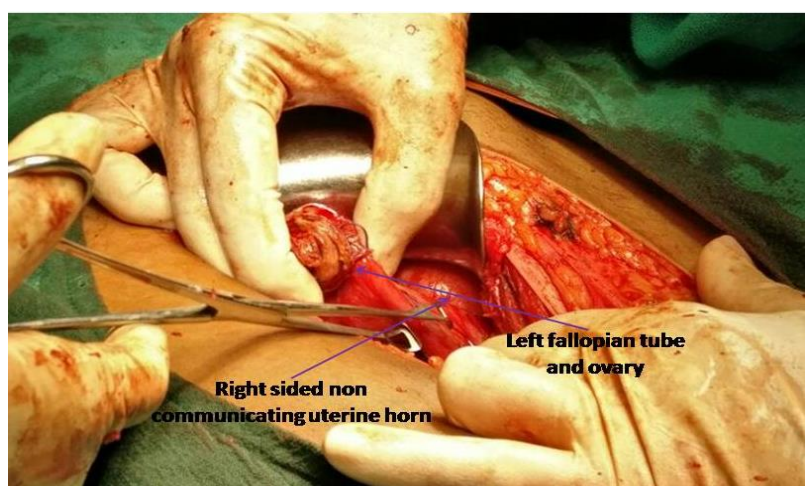

Figure 2: Right sided rudimentary noncommunicating uterine horn after excision.

A transabdominal ultrasound scan was performed with findings as follows: single intrauterine pregnancy, no fetal heart activity, femur length $2.4 \mathrm{~cm}$ and gestational age 16 wks 6 days. Her Haemoglobin was $6.4 \mathrm{~g} / \mathrm{dl}$, platelet count was $155 \times 10^{9} / \mathrm{L}$ and clotting profile was normal. Patient was given two packed cell transfusions. Termination of pregnancy was induced with intracervical folley's catheter with $100 \mathrm{mcg}$ of Misoprostol in the posterior vaginal fornix.

On expulsion of intracervical folley's 200mcg of Misoprostol was repeated every 6 hourly, for a total period of 48 hours. There were no complications associated with the attempts at termination of pregnancy. Based on failed attempts at pregnancy termination, extrauterine pregnancy was suspected.

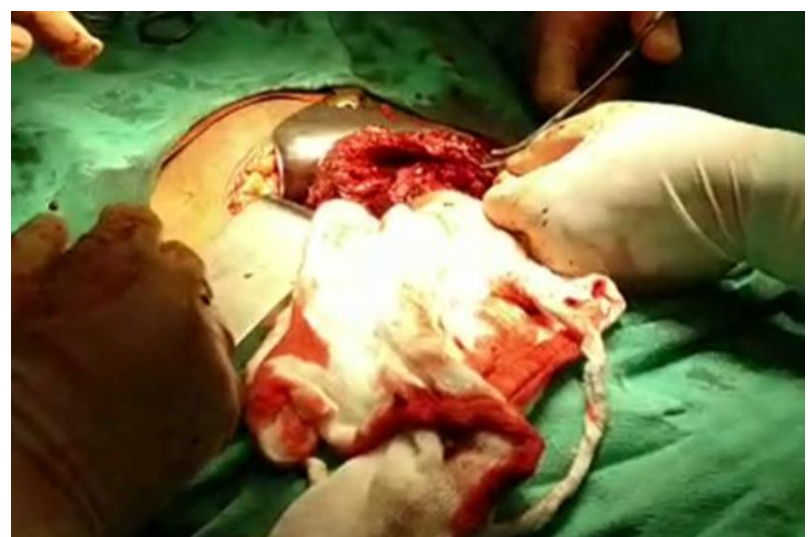

Figure 2: Left sided rudimentary non-communicating horn after excision.
Patient was taken for laparotomy under spinal anaesthesia. Abdomen opened by low transverse incision and in layers. Intraoperative findings: Bulky uterus with pregnant left rudimentary horn which was attached to the whole length of the body of the uterus. Right sided tube and ovary were healthy. Left sided tube and ovary was attached to the rudimentary horn and was adherent to the POD. Bowel loops and omentum were also adhered to the POD.

Left sided rudimentary horn was cut open and macerated fetus was delivered out along with placenta. There was no communication between rudimentary horn and the main uterus. Left sided ovarian ligament was clamped, cut and ligated and the rudimentary horn was excised after clamping it using long artery forceps. The repair was done in two layers using Vicryl 1 No. Haemostasis was achieved. Left ovary, right tube and ovary were left in situ. Both kidneys were palpated and were of normal size and in their normal position.

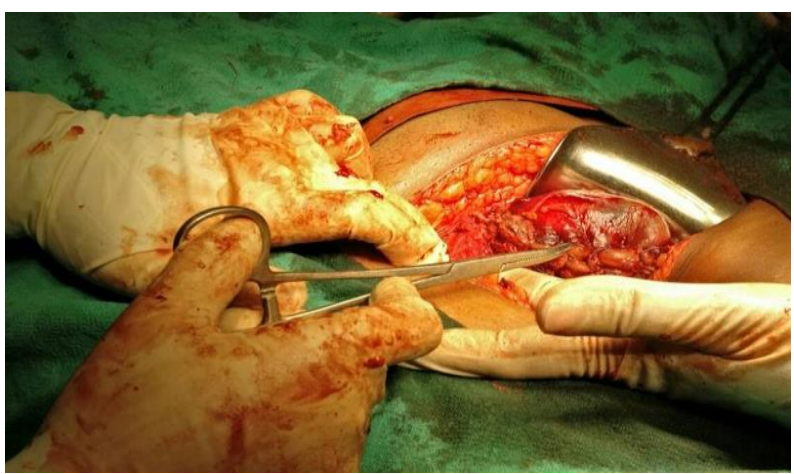

Figure 3: Repair after left sided rudimentary horn excision.

She was counseled regarding her future chances at getting pregnant. She was also educated on the need for keeping her discharge records that stated her intra operative findings for future references. She was counseled on the need for optimum antenatal care and elective caesarean section for any future pregnancy. Stitches were removed on $8^{\text {th }}$ postoperative day and patient was discharged. She was advised to undergo intravenous urography in her follow up visits, however she didn't come for follow up.

\section{Histopathology report}

Gross specimen showed a fetus with crown- rump length of $240 \mathrm{~mm}$. Section showed normal villi with a thickened smooth muscle cavity. Few endometrial glands and stroma were seen within the muscle layer. The findings were consistent with ectopic (uterine horn) gestation.

\section{DISCUSSION}

Unicornuate uterus with rudimentary horn occurs due to failure of complete development of one of the Mullerian ducts and incomplete fusion with the contralateral side. 
The incidence is estimated at 1 per $1,00,000$ to $1,40,000$ pregnancies. $^{3}$ Pregnancy in a noncommunicating rudimentary horn occurs through the transperitoneal migration of the spermatozoon or the transperitoneal migration of the fertilized ovum. ${ }^{4}$ In the past, majority of cases were diagnosed after rupture of rudimentary horn. Variable thickness of rudimentary horn musculature, poor distensability of myometrium leads to rupture. The first case of uterine rupture associated with rudimentary horn was reported in 1669 by Mauriceau. ${ }^{5}$ The timing of rupture varies from 5 to 35 weeks depending on the horn musculature and its ability to hypertrophy and dilate. 70$90 \%$ rupture before 20 weeks and can be catastrophic. ${ }^{6}$ As the uterine wall is thicker and more vascular, bleeding is more severe in rudimentary horn pregnancy rupture. Kadan and Romano described rudimentary horn rupture as the most significant threat to pregnancy and a lifethreatening situation. ${ }^{8}$

Early diagnosis of the condition is essential and can be challenging. Ultrasound, hysterosalpingogram, hysteroscopy, laparoscopy, and MRI are diagnostic tools. ${ }^{9}$ Fedele et al. have found ultrasonography to be useful in the diagnosis. ${ }^{10}$ But the sensitivity of ultrasound is only $26 \%$ and sensitivity decreases as the pregnancy advances. ${ }^{11}$ It can be missed in inexperienced hands as in our case.

Tsafrir et al. reported 2 cases of rudimentary horn pregnancy found in the first trimester by sonography and confirmed by MRI. They outlined a set of criteria for diagnosing pregnancy in the rudimentary horn. ${ }^{12}$ They are a pseudo pattern of asymmetrical bicornuate uterus; absent visual continuity tissue surrounding the gestation sac and the uterine cervix; presence of myometrial tissue surrounding the gestational sac.

Use of labor induction agents for termination of pregnancy in a rudimentary horn is unsuccessful and can lead to rupture of the horn. Nonresponders to induced abortion should be investigated with a high index of suspicion. Buntungu et al. reported a rudimentary horn pregnancy in a 6th gravida with all previous normal deliveries with a diagnosis of intrauterine fetal demise in this pregnancy where induction with misoprostol failed leading to the suspicion of ectopic pregnancy. ${ }^{13}$ They placed a Foley catheter into the uterine cavity prior to performing a transabdominal ultrasound scan, which obviously is not a preferred method of diagnosing an extrauterine pregnancy, but it proved to be a useful and cheap way of excluding an intrauterine pregnancy. This method has been used by others also to confirm an extrauterine pregnancy which proved to be a rudimentary horn pregnancy at laparotomy. ${ }^{14}$

Primary strategy of management of rudimentary horn is surgical removal. Immediate surgery is recommended by most after the diagnosis even in unruptured cases. Removal of the horn prior to pregnancy in order to prevent complications is also advised. However, conservative management, until viability is achieved, has been advocated in few selected cases if emergency surgery can be performed anytime and if the patient is well informed. A case of pregnancy progressing to the third trimester and resulting in live birth after caesarean section has been documented. ${ }^{15}$

\section{CONCLUSION}

Despite advances in ultrasound and other diagnostic modalities, prenatal diagnosis remains elusive, with confirmatory diagnosis being on laparotomy. The diagnosis can be missed in ultrasound especially in inexperienced hands and high index of suspicion is needed.

\section{Funding: No funding sources \\ Conflict of interest: None declared \\ Ethical approval: Not required}

\section{REFERENCES}

1. Hassan CHC, Kadir A, Karim A, Ismail NAM, Omar $\mathrm{MH}$. Case report of ruptured non-communicating right rudimentary horn pregnancy: an acute emergency. Acta Medica. 2011;54(3):125-6.

2. Simon C, Martinez L, Pardo F, Tortajada M, Pellicer A. Mullerian defects in women with normal reproductive outcome. Fertil Steril. 1991;56(6):11923.

3. Sevtap HK, Aral AM, Sertac B. An early diagnosis and successful local medical treatment of a rudimentary uterine horn pregnancy: a case report. Arch Gynecol Obstet. 2007;275(4):297-8.

4. Scholtz M. A full-time pregnancy in a rudimentary horn of the uterus. $\mathrm{Br} \mathrm{J}$ Obstet Gynecol. 1951;58:293-6.

5. Mauriceau F. Traite des maladaies des femmes grosses. In: Mauriceau F, eds. A Book. 1st ed. Paris, France: Compaigne des libraries; 1721.

6. O'leary JL, O'leary JA. Rudimentary horn pregnancy. Obstet Gynecol. 1963;22:371-4.

7. Chowdhury S, Chowdhury T, Azim E. Pregnancy in a non-communicating rudimentary horn of uterus: a clinical case report. Bangladesh Med J. 2010;39(1):47-8.

8. Kadan Y, Romano S. Rudimentary horn pregnancy diagnosed by ultrasound and treated by laparoscopy: a case report and review of the literature. J Minim Invasive Gynecol. 2008;15(5):527-30.

9. Lawhon BP, Wax JR, Dufort RT. Rudimentary uterine horn pregnancy diagnosed with magnetic resonance imaging. Obstet Gynecol. 1998;91(5):869.

10. Fedele L, Dorta M, Vercellini P, Brioschi D, Candiani GB. Ultrasound in the diagnosis of subclasses of unicornuate uterus. Obstet Gynecol. 1988;71(2):274-7.

11. Jayasinghe Y, Rane A, Stalewski H, Grover S. The presentation and early diagnosis of the rudimentary uterine horn. Obstet Gynecol. 2005;105(6):1456-67. 
12. Tsafrir A, Rojansky N, Sela HY, Gomori JM, Nadjari M. Rudimentary horn pregnancy: first trimester prerupture sonographic diagnosis and confirmation by magnetic resonance imaging. J Ultrasound Med. 2005;24(2):219-23.

13. Buntungu KA, Ntumy MY, Ameh EO, Obed SA. Rudimentary horn pregnancy: pre-rupture diagnosis and management. Ghana Med J. 2008;42(2):92-4.

14. Chopra S, Suri V, Aggarwal N. Rudimentary horn pregnancy: Prerupture diagnosis and management. Indian J Med Sci 2007; 61:28-29.
15. Shin JW, Kim HJ. Case of live birth in a noncommunicating rudimentary horn pregnancy. J Obstet Gynecol Res. 2005;31(4):329-31.

Cite this article as: Gaur Y, Goswami P, Meravi K. Rudimentary horn pregnancies: dilemmas in diagnosis. Int J Reprod Contracept Obstet Gynecol 2017;6:4123-6. 